\title{
Role of Mecp2 Gene in Neuro Developmental Disorders
}

\author{
Amna Batool ${ }^{1}$, Mahira Arooj ${ }^{2,3,}$ \\ ${ }^{I}$ Department of Bioinformatics and Biotechnology, International Islamic University Islamabad, Pakistan. \\ ${ }^{2}$ School of Biomedical Sciences, CHIRI Biosciences, Curtin University, Perth, WA, 6012, Australia. \\ ${ }^{3}$ Cancer Epigenetics group, The Harry Perkins Institute of Medical Research, Perth, WA, 6009, Australia.
}

\begin{abstract}
The increasing emergence of Complex Neurological Disorders (NDDs) necessitates genotypic approaches to characterize therelevant phenotypes. The analysis of complex NDDs have shown that the genetics is fundamental to such diseases. Interestingly both mutations and polymorphisms are involved, occurring in a single gene or clusters of genes.MECP2 gene is found to be engaged in wide range of neurological disordersand hence a comprehensive investigation on this gene is required to underlie the aetiology of such alarming diseases.
\end{abstract}

Keywords: Methyl-CpG Binding Protein 2(MECP2), Methyl Binding Domain (MBD), Transcriptional Repressor Domain TRD, Rett syndrome, Autism, Complex Neurological Disorder.

\section{Introduction}

Methylation of the genomic DNA is the most important modification of the eukaryotes which governs the expression of the genome. MECP2 (Methyl-CPG Binding Protein 2) is a DNA binding protein which is present excessively in Nervous system. MECP2 along with other Binding proteins (MBD1, MBD2 etc.) comprise a group of nuclear proteins capable of binding specifically to Methylated CPGs and regulating the cell expression ( $\mathrm{Na}$ et al., 2013), as well as engaged in regulation of gene at the post transcriptional level by repressing the Nuclear microRNA (Cheng et al., 2014). It is reported thatMECP2 has a dual function, it mediates both in repression as well as activation of many genes (Swanberg et al., 2009).

Wide range of mutations and duplications in MECP2 gene have been asserted in Complex Neurological disorders (Smyk et al., 2008) typically Rett syndrome, mental retardation and Autism. Interestingly both polymorphisms and mutations in this gene have been claimed to be involved.Towards this aim the screening of this gene in neurological symptoms is of utter importance which can provide a permanent solution to the congenital and life threatening neurodegenerative diseases.

\section{Structure of Methyl-CpG Binding Protein 2(MECP2) Gene}

The Methyl-CpG Binding Protein 2 (MECP2) gene is located at X chromosome; q28 and encodes a protein transcriptional regulator methyl-CpG-binding protein 2 that binds to the residues of Methylated cytosine (CpG dinucleotides) and regulate the transcriptional silencing of other genes along with Histone deacetylase and other transcriptional repressors (Hoffbuhr et al., 2002).

MECP2also regulates the gene expression at post transcriptional level as well as an important factor of neural development. It suppresses the nuclear microRNA processing by specifically binding toDGCR8(DiGeorge syndrome critical region 8), a critical component of the nuclear microRNA machinery thereby regulating the expression of gene. The interaction in turn also target the proteins: CREB, LIMK1, and Pumilio2, necessaryfor the maturation of nervous system and also inhibits the growth of dendritic and spine (Cheng et al., 2014). Post translational modifications like phosphorylation, SUMOylation, and acetylation have a considerable effect on MECP2 proteinwhich cater more dimensions to its regulatorytasks (Cheng and Qiu, 2014).

The Transcript/GENE length of $M E C P 2$ gene is 10,505 bps, length of Translation/PROTEIN is 486 amino acids and contains 4 Exons (ENSEMBL ID: ENST00000303391.10) as shown in figure 3.1. 


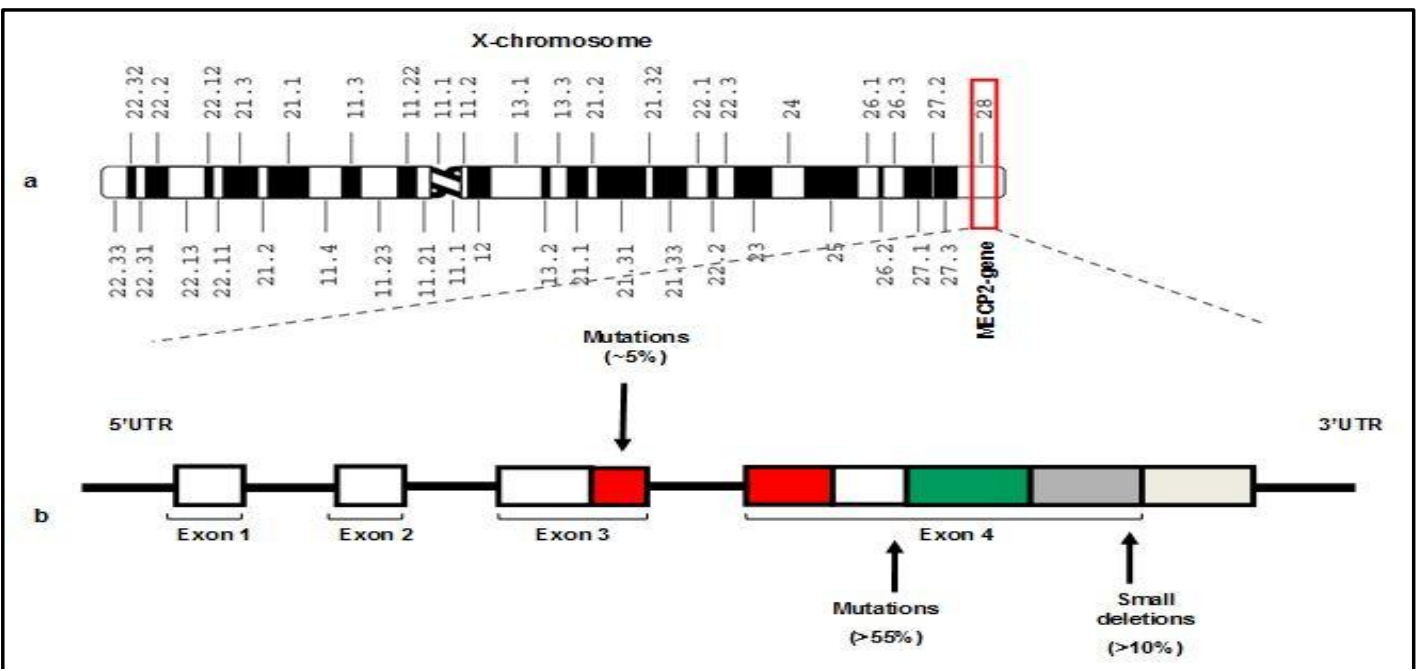

Figure 3.1The $M E C P 2$ gene consists of 4 exons. The majority of mutations among found in exon 4 . The Untranslated region show the direction of the gene; from 5' UTR to 3' UTR (Verhoevenet al., 2011).

The isoforms of $M E C P 2$ include; MeCP2_e2 in which all four EXONs are present and MeCP2_e1 in which EXON 2 is spliced. The level of expression of these two isoforms differ among tissues, with MeCP2_e1 has the highest expression in brain, whereas MeCP2_e2 is presentsignificantly in liver, placenta and skeletal muscle (Itoh et al.,2012) as shown in figure 3.2.

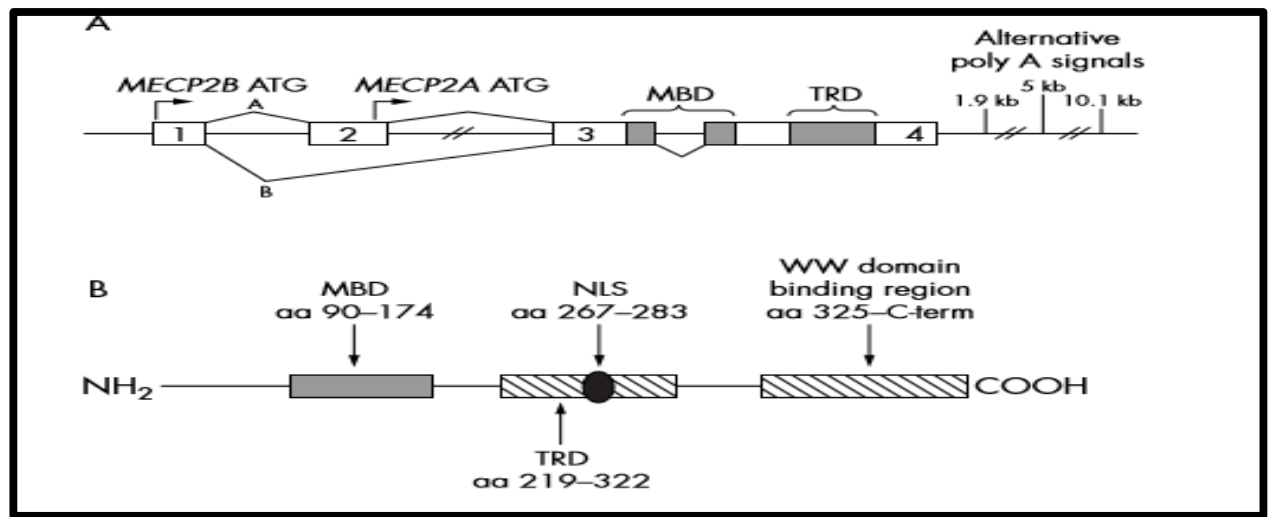

Figure 3.2The architecture MECP 2 gene and mRNA is shown (Kriaucionis and Brid, 2004; Mnatzakanianet al., 2004). The figure demonstrates the alternative splicing. The $\beta$ isoform of the gene is presented above the gene at position ' $\mathrm{A}$ ' and the $\alpha$ isoform is present beneath the gene at ' $\mathrm{B}$ '. The expression of $\beta$ isoform is dominant in nervous system and anomalies in this isoform is adequate induce the Rett phenotypes. The protein is 486 amino acid long and contains MBD domain; TRD domain; NLS; and WW domain (Weaving et al., 2005).

\section{Functional Domains of MECP2}

There are three functional domains of $M E C P 2$; Methyl CpG binding domain (MBD), Transcription repressor domain (TRD), C terminal domain (CTD) as shown in figure 3.2.

\subsection{The Methyl-CPG Binding Domain (MBD)}

The methyl-CpG binding domain binds particularly to Methylated-CpGs. It is 85 amino acid long; and is present with exon 3 and 4; and is crucial for chromatin remodeling. Studies have shown that the MBD tailor a wedge-shaped molecular structure as shown in figure 4.1.It contains a hydrophobic pocket having the side chains Tyr123 and Ile125 present on the beta-sheet face is thesite of contact with the Methyl groups of the cytosine residues (Wakefieldet al., 1999). The N-terminus of the MBD consist of amino acid identical the HMG (high mobility group proteins) that regulate DNA activities such as transcription, translation etc. Recently the interaction between the N-terminal region and theRepressive Chromatin Regulator Heterochromatin protein 1 (HP1) has been shown which is the key factor in formation of transcriptionally inactive heterochromatin (Singh et al., 2008). 


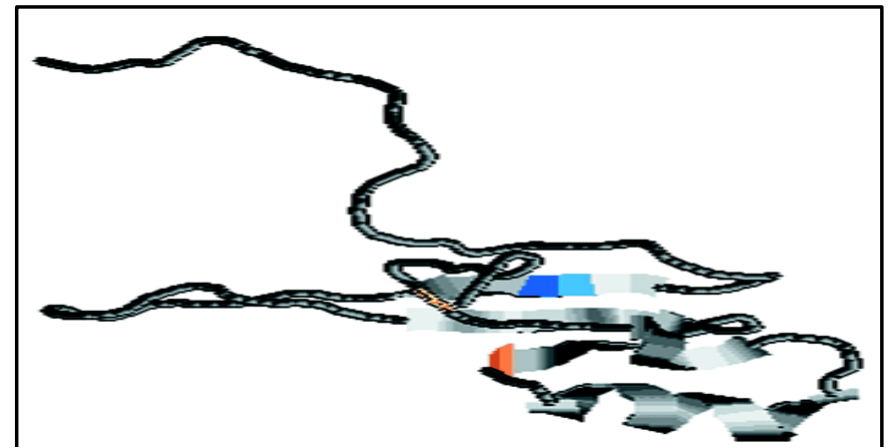

Figure 4.1The exemplifiedstructure of the Methyl-CpG binding domain (Wakefield et al., 1999). Three of the four $\beta$-sheets are shown to be associated with modified methylated $\mathrm{CpG}$ in the major groove. Mutations are shows as; R106W in blue R133C in orange and T158M in yellow (Wakefield et al., 1999; Berman et al., 2000; Dragichet al., 2000).

\subsection{TheTranscriptional Repressor Domain (TRD)}

A transcriptional repression domain 104 amino acid long; present within exon 4; with co-repressor complexes, repress the transcription by the de-acetylation of the histones, with subsequent amendment of DNA into hetero-chromatin (Jones et al., 1998; Nan et al., 1998). MECP2 interacts with the Sin3A/HDACI or $\mathrm{Ski} / \mathrm{NcoR} / \mathrm{HDACII}($ repression complexes) to perform this task (Kokura et al., 2001). Moreover, MECP2has independent silencing capabilities. This domain also contains the Nuclear Localization Signals (NLS).

\subsection{The C Terminal Domain (CTD)}

This Domain (residues 384-387) particularly binds to WW domains of (group II) Splicing factors including; Formin binding protein II and Huntington yeast protein C. When the binding region of the WW domain was cut short by 48 amino acids present at $\mathrm{C}$ terminus, involved in Rett syndrome, caused a decreased or failure of WW domain binding activity. Furthermore, the reduction of the WW domain binding activity is also linked with mild to moderate intellectual disability in males (Buschdorf and Stratling, 2004). The CTD also contains the chromatin binding regionswhich are needed for the remodeling of the chromatin (Nikitina et al., 2007).

There are common orthologues of $M E C P 2$ in monkey, rat, xenopus, mouse, and zebrafish, suggesting the key roles of $M E C P 2$ throughout vertebrate evolution (Weaving et al., 2005).

\section{Spectrum of MECP2 Mutation}

The spectrum of MECP2 mutation is broad including; Nonsense mutations, Missense mutations, Frameshift mutations, as well as micro-deletions and mutations in regulatory elements and intronic regions of MECP2 (Bourdonaet al., 2001).It has been noted that missense mutations are on average less destructive than nonsense mutations and anomalies in the methyl binding domain are more apparent (Schanenet al., 2004; Leonard et al., 2003; Colvin et al., 2004; Weaving et al., 2005).

Missense mutations appear within the Methyl binding domain; (R106W, R133C, F155S and T158M), and one nonsense mutation; (L138X), abolished the precise binding of MECP2 to the methylated DNA which is associated with several neurological phenotypes.Nonsense mutations; (L138X, R186X, E235X, R255X, R270X, V288X and R294X) and two missense mutations; one inside the Transcriptional repressor domain; (R306C) and other one in the $\mathrm{C}$ terminal domain; (E397K) were found. The nonsense mutations resulted in non-functional protein product which were unable to suppress the transcription, as opposed to missense mutations which kept the ability to repress the transcription (Timur and Alan, 2000).

The MECP2 gene has frequent mutations and duplications in wide range of neurological disorder (Villard et al., 2007; Smyk et al., 2008). It was illustrated that there is a reduced expression MECP2 in $79 \%$ of autism samples of cortex (Nagarajanet al., 2006).In Rett syndrome(RTT) patients there is a normal early development superseded by regression and motor anomalies which is attributed to mutations in MECP2(Mitchel, 2011).An allele of MECP2 (hypomorphic) shows abnormal social behavior in transgenic mouse. (Samacoet al., 2008; Kerr et al., 2008) further suggesting the reduced expression of MECP2 in autistic behavior (Susan et al., 2009).

Females with MECP2 mutations show infantile autism, mild intellectual disability and reserved speech (Percy, 2002; Beyer et al., 2002). Males display phenotypes including fatal encephalopathy in newborns, severe mental retardation, seizures, tremor, lack of muscle coordination and psychiatric symptoms (Percy, 2002). Females render milder phenotypesdue to the X-chromosome inactivation generally skewed X-chromosome inactivation occurs (Amir et al., 2000). It has also been found that the connection between theMECP2 and the 
ATRXproteins (chromatin proteins) is disturbed by the mutations which results inintellectual disabilities (Nan $e t$ al., 2006).

\section{MECP2 as Novel Oncogene}

A genome wide sequence has also identified $M E C P 2$ as a novel oncogene. Many cell lines of cancer have been elaborated which display overexpression of the MECP2 and rely onMECP 2 for their proliferation. The alterations in the MECP2 and the members of RAS family are mutually exclusive in various types of cancer. The isoforms of $M E C P 2$ activate signal transduction networks. The recovery of KRAS-cell lines depends upon the $M E C P 2$ after the suppression of KRAS in the same way the growth of MECP2-cell lines rely upon KRAS. The binding of the MECP2 to the 5-hydroxymethylcytosine (5hmC) is needed for effective transformation a key to epigenetics. These findings propose that MECP2can be considered as a novel oncogene (Neupaneet al., 2015).

\section{Dual Role of MECP2}

It is a chromatin-associated protein (Kumar et al., 2008) which mediates both in transcription; activation and repression (Yasuiet al., 2007; Chahrouret al., 2008; Swanberg et al., 2009). To find out the dual role of $M E C P 2$, patterns of gene expression in the cerebellum of $M E C P 2$-null and $M E C P 2-T g$ mice were studied, posing the $M E C P 2$ duplication syndrome and RTT phenotypes. It was illustrated that theirregular dosage of $M E C P 2$ give rise to changes in the expression many genes in the cerebellum. The level of expression of this gene was increased in MECP2-Tg mice and decreased in MECP2-null mice, confirming the dual role of $M E C P 2$. This data suggested that altered levels of $M E C P 2$ either a gain or a loss cause a change in level of expression in various areas of brain and some of them are global shifts (Shacher et al., 2009) as shown in figure 7.1 .

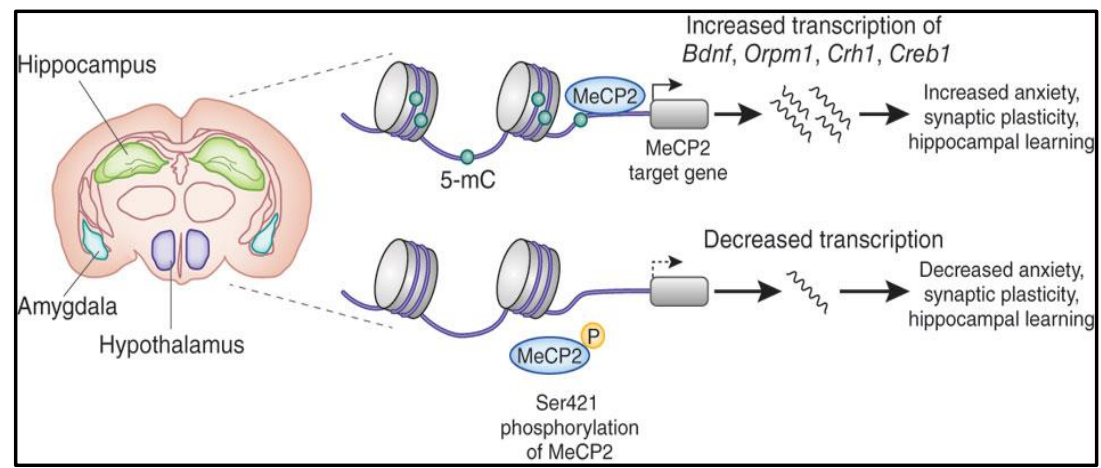

Figure 7.1 Dual function of $M E C P 2$ is shown. In adult mouse forebrain, promoter-bound- $M E C P 2$ increases the expression of important regulatory factors that regulate moods, emotions, learning and memory. In vivo, Ser421 phosphorylation of $M E C P 2$ decreases the affinity of promoter binding and consequently the gene expression, with alterations in behavioral states. These observations were elucidated by research in the amygdala,

hypothalamus and hippocampus regions of MECP2 mutant and wild-type mice (Jakovcevski and Akbarian, 2012).

\section{MECP2Expression in Central Nervous System (CNS)}

The neurons contain the maximum levels of $M E C P 2$, which is originally present at low amounts andraises over the course of neuron development, and reaches its highest level in matured neuron(Balmeret al., 2003). Studies reveal that the individuals suffering from RTT (Rett syndrome) have lesser population of neurons and their dendrites are less complex as opposed to the control samples further supporting the function of $M E C P 2$ in neuronprogression. Cells of Glia also contains observable levels of $M E C P 2$ protein. It has also beenindicated that the astrocytes possesstheMECP2 expression critical for the RTT phenotypes (Ballaset al., 2009; Maezawaet al., 2009; Gonzales and LaSalle, 2010). Italso modulate thegenes like Bdnf (brain-derived neurotropic factor) and JUNB. The EGR2 gene (early growth response 2 gene) isneeded for neuronal function as well as early development of hindbrain, has its binding sites in the promoter regions of neuronal genes including MECP2 gene (Swanberget al., 2009).

An experiment was conducted in which the expression level of $M E C P 2$ protein was kept normal in the nervous system, but is deficient in rest of the body. Wild type and $M E C P 2$ deficient mice were then compared and it was shown that the majority of neurological symptoms were absent. However bone abnormalities, fatigue, and hypo-activity was observed, which confirms brain as the primary organ for $M E C P 2$ associated phenotypes, but it also suggests that less extreme form of disorder may arise independent of the nervous system (Ross et al., 2016). 
Furthermore there is an increased expression of $M E C P 2$ especially in the hippocampus, cortex, and cerebellum which turns out to be associated in neuronal maturation. It has been proved that the $M E C P 2$ is found in the post-synaptic compartments of neurons and its nucleus, which implies that the $M E C P 2$ has a role in synaptic activity and performs transcription regulation through it (Aber et al., 2004; Weaving et al., 2005).

The neuronal transcription and retro-transposition of Long interspersed nuclear elements-1L, get elevated in the absence of $M E C P 2$ gene. Utilizing human induced pluripotent stem cells, neuronal progenitor cells were acquired, it was explained that the patients with neurologic symptoms, carrying the $M E C P 2$ mutations, are vulnerable for L1 retro-transposition. These findings pose anadditional challenge to the molecular events which give rise to the disorders of the CNS (Muotriet al., 2010).

\section{MECP2 Duplication Syndrome}

Duplications of the Xq28 region (locus of MECP2) are the most frequent chromosomal abnormalities associated with intellectual disability, especially in males. These duplications include interstitial duplications mediated by segmental duplication and terminal duplications. The most commonly duplicated region includes MECP2 gene, with atleast duplicated size of $0.2 \mathrm{Mb}$. Duplications also occurs in telomeric nearby regions, which include GDP dissociation inhibitor 1 gene (GDI1); and Ras-associated gene (RAB39B); are individually linked with intellectual disabilities. Magnetic Resonance Imaging of brain reveals abnormalities in the white matter, which is consistently found in patients with MECP2 duplications (Yamamoto et al., 2014). Phenotypes of this duplication includes; decreased muscle tone, delay in psychomotor skills, intellectual disability, apraxia, contraction of muscle, seizures and periodic respiratory infections. Females have also been observed to show milder phenotypes. Most of the affected males die before reaching twenty five. Additionally autistic symptoms and gastrointestinal malfunctioning have also been noted in boys (Pagonet al., 2008).

\section{Conclusion}

Significant amount of findings have been presented concerning the role ofMECP2 gene. The etiology of neurological disorders lies in the complex genetic networks and their interactions. Thus considerable researches have been carried out to analyze the crucial and precise role of $M E C P 2$. Interestingly bothrarevariations and common polymorphisms within this geneare found to belinked with the critical phenotypes of CNS, which necessitates the thorough investigation of $M E C P 2$, in order to implement practical diagnostic approaches. Various gene therapy approaches have been used based on the available genetic information for treating the neurological disorders. More recent approach involves whole organ being synthesized using reprogrammed stem cells and also repair of damaged tissue using stem cells regenerative therapies which offers a great potential towards the therapy of these complex NDDs.

\section{References}

[1] Aber KM, Nori P, MacDonald SM, Bibat G, Jarrar MH, Kaufmann WE (2003). Methyl-CpG-binding protein 2 is localized in the postsynaptic compartment: an immunochemical study of subcellular fractions. Neurosci 116: 77-80.

[2] Amir RE, Veyver IB, Schultz R, Malicki DM, Tran CQ, Dahle EJ, Philippi A, Timar L, Percy AK, Motil KJ (2000). Influence of mutation type and X chromosome inactivation on Rett syndrome phenotypes. Ann. Neurol 47: 670-679.

[3] Ballas N, Lioy DT, Grunseich C, Mandel G (2009). Non-cell autonomous influence of MeCP2-deficient glia on neuronal dendritic morphology. Nat Neurosci 12: 311-7. doi: 10.1038/nn.2275.

[4] Balmer D, Goldstine J, Rao YM, LaSalle JM (2003). Elevated methyl-CpG-binding protein 2 expression is acquired during postnatal human brain development and is correlated with alternative polyadenylation. J Mol Med 8:61-68.

[5] Berman HM, Westbrook J, Feng Z, Gilliland G, Bhat TN, Weissig H, Shindyalov IN, Bourne PE (2000). The Protein Data Bank. Nucleic Acids Res 28: 235-242.

[6] Beyer KS, Blasi F, Bacchelli E, Klauck SM, Maestrini E, Poustka A (2002). Mutation analysis of the coding sequence of the MECP2 gene in infantile autism. Hum. Genet 111: 305-309.

[7] Bourdona V, Philippea C, Bienvenub T, Koenigc B, Tardieud M, Chellyb J, Jonveaux P (2001). Evidence of somatic mosaicism for aMECP2 mutation in females with Rett syndrome: diagnostic implications. J Med Genet 38: 867-871.

[8] Buschdorf JP and Stratling WH (2004). A WW domain binding region in methyl-CpGbinding protein MeCP2: impact on Rett syndrome. J Mol Med 82: 135-43.

[9] Chahrour M, Jung SY, Shaw C, Zhou X, Wong ST, Qin J, Zoghbi HY (2008). MeCP2, a key contributor to neurological disease, activates and represses transcription. Science 320: 1224-1229.

[10] Cheng TL and Qiu Z (2014). MeCP2: multifaceted roles in gene regulation and neural development. Neurosci Bull. 30 :601-9. doi: 10.1007/s12264-014-1452-6.

[11] Cheng TL, Wang Z, Liao Q, Zhu Y, Zhou WH, Xu W, Qiu Z (2014). MeCP2 suppresses nuclear microRNA processing and dendritic growth by regulating the DGCR8/Drosha complex. Dev Cell. 28 :547-60. doi: 10.1016/j.devcel.2014.01.032.

[12] Colvin L, Leonard H, de Klerk N, Davis M, Weaving L, Williamson S, Christodoulou J (2004). Refining the phenotype of common mutations in Rett syndrome. J Med Genet41:25-30.

[13] Dragich J, Houwink-Manville I, Schanen C (2000). Rett syndrome: a surprising result of mutation in MECP2. Hum. Mol. Genet 9: 2365-2375.

[14] Gonzales ML and LaSalle JM (2010). The role of MeCP2 in brain development and neurodevelopmental disorders. Curr Psychiatry Rep 12: 127-34. doi: 10.1007/s11920-010-0097-7.

[15] Hoffbuhr KC, Moses LM, Jerdonek MA, Naidu S, Hoffman EP (2002). Associations between MeCP2 mutations, X-chromosome inactivation, and phenotype. Ment Retard Dev Disabil Res Rev. 8: 99-105. 
[16] Itoh M, Tahimic CGT, Ide S, Otsuki A, Sasaoka T, Noguchi S, Oshimura M, Goto Y, Kurimasa A (2012). Methyl CpG-binding Protein Isoform MeCP2_e2 Is Dispensable for Rett Syndrome Phenotypes but Essential for Embryo Viability and Placenta Development. J Biol Chem. 287(17):13859-67.

[17] Jakovcevski M and Akbarian S (2012). The complex pathophysiology of MeCP2. Nature Med 18: 1194-1204.

[18] Jones PL, Veenstra GJ, Wade PA, Vermaak D, Kass SU, Landsberger N, Strouboulis J, Wolffe AP (1998). Methylated DNA and $\mathrm{MeCP} 2$ recruit histone deacetylase to repress transcription. Nat Genet, 19: 187-91.

[19] Kerr B, Alvarez-Saavedra M, Sáez MA, Saona A, Young JI (2008). Defective body weight regulation, motor control and abnormal social interactions in Mecp2 hypomorphic mice. Hum Mol Genet. 17: 1707-1717.

[20] Kokura K, Kaul SC, Wadhwa R, Nomura T, Khan MM, Shinagawa T, Yasukawa T, Colmenares C, Ishii S (2001). The Ski protein family is required for MeCP2-mediated transcriptional repression. J Biol Chem 276: 34115-21.

[21] Kriaucionis S and Bird A (2004). The major form of MeCP2 has a novel N-terminus generated by alternative splicing. Nucl Acid Res 32: 1818-23.

[22] Kumar A, Kamboj S, Malone BM, Kudo S, Twiss JL, Czymmek KJ, LaSalle JM, Schanen NC (2008). Analysis of protein domains and Rett syndrome mutations indicate that multiple regions influence chromatin-binding dynamics of the chromatin-associated protein MECP2 in vivo. J. Cell. Sci 121: 1128-1137.

[23] Leonard H, Colvin L, Christodoulou J, Schiavello T, Williamson S, Davis M, Ravine D, Fyfe S, de Klerk N, Matsuishi T, Kondo I, Clarke A, Hackwell S, Yamashita Y (2003). Patients with the R133C mutation: is their phenotype different from patients with Rett syndrome with other mutations? J Med Genet 40: e52.

[24] Maezawa I, Swanberg S, Harvey D, LaSalle JM, Jin LW (2009). Rett syndrome astrocytes are abnormal and spread MeCP2 deficiency through gap junctions. J Neurosci 29: 5051-61. doi: 10.1523/JNEUROSCI.0324-09.2009.

[25] Mitchell KJ (2011). The genetics of neurodevelopmental disease. Curr opin neurobiol21: 197-203. doi: 10.1016/j.conb.2010.08.009.

[26] Mnatzakanian GN, Lohi H, Munteanu I, Alfred SE, Yamada T, MacLeod PJ, Jones JR, Scherer SW, Schanen NC, Friez MJ, Vincent JB, Minassian BA (2004). A previously unidentified MECP2 open reading frame defines a new protein isoform relevant to Rett syndrome. Nat Genet 36339-41.

[27] Muotri AR, Marchetto MCN, Coufal NG, Oefner R, Yeo G, Nakashima K, Gage FH (2010). L1 retrotransposition in neurons is modulated by MeCP2. Nature 468: 443-446.

[28] Na ES, Nelson ED, Kavalali ET, Monteggia LM (2013). The Impact of MeCP2 Loss- or Gain-of-Function on Synaptic Plasticity. Neuropsychopharmacology. 38: 212-219.

[29] Nagarajan RP, Hogart AR, Gwye Y, Martin MR, LaSalle JM (2006). Reduced MeCP2 expression is frequent in autism frontal cortex and correlates with aberrant MECP2 promoter methylation. Epigenetics 1: 1-11.

[30] Nan X, Hou J, Maclean A, Nasir J, Lafuente MJ, Shu X, Kriaucionis S, Bird A (2006). Interaction between chromatin proteins MECP2 and ATRX is disrupted by mutations that cause inherited mental retardation. Cross mark 104: 2709-2714.

[31] Nan X, Ng HH, Johnson CA, Laherty CD, Turner BM, Eisenman RN, Bird A (1998). Transcriptional repression by the methylCpG-binding protein MeCP2 involves a histone deacetylase complex. Nature 393: 386-9.

[32] Neupane M, Clark AP, Landini S, Birkbak NJ, Eklund AC, Lim E, Culhane AC, Barry WT, Schumacher SE, Beroukhim R, Szallasi Z, Vidal M, Hill DE, Silver DP (2016). MECP2 Is a Frequently Amplified Oncogene with a Novel Epigenetic Mechanism That Mimics the Role of Activated RAS in Malignancy. Cancer Discov. 6: 45-58.

[33] Nikitina T, Shi X, Ghosh RP, Horowitz-Scherer RA, Hansen JC, Woodcock CL (2007). Multiple modes of interaction between the methylated DNA binding protein MeCP2 and chromatin. Mol Cell Biol. 3: 864-77.

[34] Pagon RA, Adam MP, Ardinger HH, Wallace SE, Amemiya A, Bean LJH, Bird TD, Fong CT, Mefford HC, Smith RJH, Stephens K (2008). MECP2 Duplication Syndrome. GeneReviews $®$.

[35] Percy AK (2002). Rett syndrome. Current status and new vistas. Neurol. Clin 20: 1125-1141.

[36] Ross PD, Guy J, Selfridge J, Kamal B, Bahey N, Tanner E, Gillingwater TH, Jones RA, Loughrey CM, McCarroll CS, Bailey ME, Bird A, Cobb S (2016). Exclusive expression of MeCP2 in the nervous system distinguishes between brain and peripheral Rett syndrome-like phenotypes.Hum Mol Genet. pii: ddw269.DOI: 10.1093/hmg/ddw269.

[37] Samaco RC, Fryer JD, Ren J, Fyffe S, Chao HT, Sun Y, Greer JJ, Zoghbi HY, Neul JL (2008). A partial loss of function allele of methyl-CpG-binding protein 2 predicts a human neurodevelopmental syndrome. Hum. Mol. Genet. 17: 1718-1727.

[38] Schanen C, Houwink EJ, Dorrani N, Lane J, Everett R, Feng A, Cantor RM, Percy A (2004). Phenotypic manifestations of MECP2 mutations in classical and atypical Rett syndrome. Am J Med Genet 126A: 129-40.

[39] Shachar SB, Chahrour M, Thaller C, Shaw CA, Zoghbi HY (2009). Mouse models of MeCP2 disorders share gene expression changes in the cerebellum and hypothalamus. Hum. Mol. Genet 18: 2431-2442.

[40] Singh J, Saxena A, Christodoulou J, Ravine D (2008). MECP2 genomic structure and function: insights from ENCODE. Nucleic Acids Res 36: 6035-6047

[41] Smyk M, Obersztyn E, Nowakowska B, Nawara M, Cheung SW, Mazurczak T, Stankiewicz P, Bocian E (2008).Different-sized duplications of Xq28, including MECP2, in three males with mental retardation, absent or delayed speech, and recurrent infections. Am J Med Genet B Neuropsychiatr Genet. 147B(6): 799-806.

[42] Susan E. Swanberg SE, Raman P. Nagarajan RP, Peddada S, Yasui DH, LaSalle JM (2009). Reciprocal co-regulation of EGR2 and MECP2 is disrupted in Rett syndrome and autism. Hum Mol Genet 18: 525-534.

[43] Swanberg SE, Nagarajan RP, Peddada S, Yasui DH, LaSalle JM (2009). Reciprocal co-regulation of EGR2 and MECP2 is disrupted in Rett syndrome and autism. Hum. Mol. Genet 18: 525-534.

[44] Timur MY and Alan PW (2000). Functional consequences of Rett syndrome mutations on human MeCP2. Nucleic Acids Res. 28: 4172-4179.

[45] Verhoeven W, Egger J, Feenstra I (2011). Autism Spectrum Disorders: The Role of Genetics in Diagnosis and Treatment. Medicine. ISBN 978-953-307-495-5

[46] Villard L (2007). MECP2 mutations in males. J. Med. Genet. 44: 417-423.

[47] Wakefield RI, Smith BO, Nan X, Free A, Soteriou A, Uhrin D, Bird AP, Barlow PN (1999). The solution structure of the domain from MeCP2 that binds to methylated DNA. J MolBiol 291: 1055-65.

[48] Weaving LS, Ellaway CJ, 'cz JG, Christodoulou J (2005). Rett syndrome: clinical review and genetic update. J Med Genet 42 : 1-7.

[49] Yamamoto T, Shimojima K, Shimada S, Yokochi K, Yoshitomi S, Yanagihara K, Imai K, Okamoto N (2014). Clinical impacts of genomic copy number gains at Xq28. Human Genome Variation 1: 14001.

[50] Yasui DH, Peddada S, Bieda MC, Vallero RO, Hogart A, Nagarajan RP, Thatcher KN, Farnham PJ, Lasalle JM (2007). Integrated epigenomic analyses of neuronal MeCP2 reveal a role for long-range interaction with active genes. Proc Natl Acad Sci U S A. 104: 19416-21. 